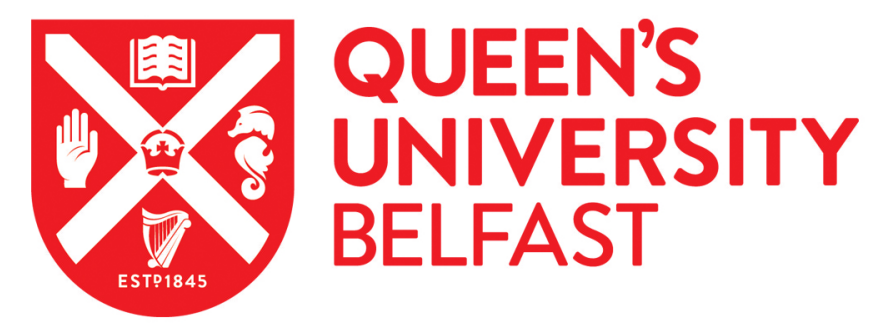

\title{
University Business Models in Disequilibrium: Engaging Industry and End Users within University Technology Transfer Processes
}

McAdam, M., Miller, K., \& McAdam, R. (2017). University Business Models in Disequilibrium: Engaging Industry and End Users within University Technology Transfer Processes. $R$ \& D Management. https://doi.org/10.1111/radm.12265

Published in:

$R$ \& D Management

Document Version:

Peer reviewed version

Queen's University Belfast - Research Portal:

Link to publication record in Queen's University Belfast Research Portal

Publisher rights

Copyright 2017 RADMA and John Wiley \& Sons Ltd.

This work is made available online in accordance with the publisher's policies. Please refer to any applicable terms of use of the publisher.

\section{General rights}

Copyright for the publications made accessible via the Queen's University Belfast Research Portal is retained by the author(s) and / or other copyright owners and it is a condition of accessing these publications that users recognise and abide by the legal requirements associated with these rights.

Take down policy

The Research Portal is Queen's institutional repository that provides access to Queen's research output. Every effort has been made to ensure that content in the Research Portal does not infringe any person's rights, or applicable UK laws. If you discover content in the Research Portal that you believe breaches copyright or violates any law, please contact openaccess@qub.ac.uk. 
University Business Models in Disequilibrium - Engaging industry and end users within university technology transfer processes.

\section{Abstract}

This paper explores how greater engagement with industry and end users has influenced the University Technology Transfer Business Model. In order to achieve this, we adopt a qualitative methodology which draws upon case study evidence of two case universities located in a particular region. The findings, represented in a conceptual framework depict a hybrid University Technology Transfer Business Model which is in a state of permanent disequilibrium as a result of path dependency and organisational culture. This permanent disequilibrium was found to cause challenges in relation to scarce resource allocation and also impacted upon the willingness and ability of academics to engage with industry and end users throughout the technology transfer process. This paper contributes to an emerging stream of research on hybrid business models by identifying the challenges of permanent disequilibrium where multiple and conflicting stakeholder goals compete for legitimacy and scarce resources. From a policy and practitioner viewpoint, this research draws attention to the complexities of university, government, industry and end user (Quadruple Helix stakeholders) engagement and the implications of such on university strategy where conflicting dominant logics can cause challenges with alignment of organisational processes and mechanisms.

Key words: Hybrid Business Models; University Technology Transfer Business Model; University-Industry Engagement

\subsection{Introduction}

In the face of a changing global economy, innovation policy specifically stipulates the need for universities to engage more fully with both industry and more recently with societal based endusers to enhance commercialisation success. These collaborations are considered important in the fostering of co-creational innovation which not only address societal needs but are a core 
source of sustainable economic growth (Hodges and Dubb, 2012). This has resulted in a transition from Triple Helix (TH) (university, government and industry) to Quadruple Helix $(\mathrm{QH})$ (university, government, industry and end users) structures within regions (Arnkil et al., 2010; Carayannis and Rakhmatullin, 2014); with QH structures including a fourth stakeholder group, societal based end-users, in addition to government, industry and universities (traditionally found within triple helix structures) (Carayannis and Campbell, 2009). Indeed, the QH approach has emerged as a response to the criticisms raised against the TH model, where innovation outcomes have not conformed to expected levels signalling the need for more co-creational innovation (Carayannis and Rakhmatullin, 2014). Despite Universities being regarded as a core stakeholder within an innovating region, there is a scarcity of research relating to the challenges faced by universities attempting to integrate industry and end users within their innovation processes and so moving to $\mathrm{QH}$ structures and the subsequent impact of such on their business models (Miller et al., 2014).

In this paper, we posit that universities have several business models with the core remits of teaching, research, business engagement and university technology transfer representing distinct business models. In doing so, we acknowledge research by Gaus and Raith (2016) who view the entrepreneurial university as a singular business model with separate models of value creation. However, we concur with Casadesus-Masanell and Tarijan (2012) in arguing that organisations can have numerous distinct but inter-related business models representing core aspects of their business. Accordingly, within this paper, we focus specifically on the University Technology Transfer Business Model (UTTBM) as a viable context to explore the challenges facing universities in more fully engaging with QH stakeholders. This paper therefore aims to explore how the need for universities to more fully engage with industry and end users, reflecting a move from TH to QH structures has influenced the UTTBM. In order 
to achieve this, we draw upon case study evidence of two differing universities, in terms of research and academic enterprise remits, located in a particular region over a six year period.

In so doing we contribute to the business model literature through a more nuanced understanding of the complexity of changing business models (Demil et al., 2015; Wirtz et al., 2015) within the university context. In particular, we contribute to the limited body of research on hybrid business models (Huyghe et al., 2014; Hahn and Spieth, 2014) by revealing how a hybrid business model can emerge involuntarily within universities as a result of policy where there is a need to engage more fully with QH stakeholders who often have conflicting goals and objectives. This hybridity can cause a permanent disequilibrium which in turn raises challenges in relation to scarce resource allocation and impacts upon the willingness and ability of academics to engage with industry and end users throughout the technology transfer process. This has implications for universities being faced with increasing expectations from government and internal strategic goals to collaborate with external stakeholders. This research also extends business model theory and practice by taking a micro foundation lens to explore the challenges of business model development which involves diverse stakeholders within a university context.

\subsection{Theoretical Development - UTTBM as an Activity System}

Recent literature and policy has called for universities to re-assess their business models (Miller et al. 2014), however, the term is used ambivalently with a lack of reification or empirical exploration of the complexity of university business models in practice (s). In general, research to date on business models is fragmented and debate continues regarding how they are defined (DaSilva and Trkman, 2014; Wirtz et al., 2015). For the purposes of this paper, we adopt Zott and Amit's (2010:216) definition of a business model as an activity system comprising of a 'system of interdependent activities that transcend the focal firm and spans its boundaries'. This 
definition was deemed appropriate given the interdependent nature of business models in the university sector where value must be co-created for a wide range of regional stakeholders. The activity system perspective aligns with the UTTBM context, where the 'focal firm' of Zott and Amit's (2010) conceptualisation is the UTT entity and is typically represented by the Technology Transfer Office (TTO) and is embedded within a network of regional stakeholders. An activity system perspective places emphasis on business model design which consists of design elements and design themes. Spieth, et al. (2014) note a lack of research exploring the processes involved in the design and implementation of business models, despite the ability to implement changes to the design of a business model considered key to sustaining a competitive advantage within turbulent environments. In the context of the UTTBM, the ability to integrate more collaborative processes involving industry and end users is one such turbulent environment, representing a transition from operating from within $\mathrm{TH}$ to $\mathrm{QH}$ structures.

Universities are complex, bureaucratic organisations which often experience high liability from path dependency and organisational inertia (Hodges and Dubb, 2012) which is ultimately underpinned by their culture. For example, Krucken (2003) argues that the path dependent character of universities's structures, practices and identities often results in universities adapting existing practices rather than engaging in institutional change. Furthermore, Howell and Annansingh (2013) identify that both culture and path dependency impact upon norms relating to knowledge generation and sharing within universities. Therefore, it can be derived that the ability to more fully engage with diverse $\mathrm{QH}$ stakeholders may be limited by both organisational culture and path dependency.

Drawing on stakeholder theory, it is noted that engaging more fully with any type stakeholders causes challenges for any organisation (Mitchell et al., 1997; Friedman et al., 2002; Miles, 2012). Indeed Miller et al., (2014) identify that in a university context, diverse stakeholders often have conflicting objectives which result in power relationships whereby 
stakeholders try to exert their salience over the university business model to achieve their own objectives. This may result in what Demil and Locoq (2010) term 'disequilibrium' within a business model where multiple and conflicting stakeholder objectives compete for legitimacy and scarce resources. This disequilibrium can be permanent or temporary and is the result of hybridity in the business model (Pache and Santos, 2010). Hybridity occurs when there is competing elements within an organisation (Furr, 2016) which consequently causes strategic challenges. Table 1 illustrates the main theoretical constructs (and related dimensions) currently used to explain hybridity.

From the literature, it was identified that universities are facing strategic challenges in responding to the need to embed industry and end users at all stages of the technology commercialisation process (from concept development to commercialisation) (Carayannis and Rakhmatullin 2014; Miller et al., 2014). This has led to the need to re-evaluate their university technology transfer business model to reflect a move away from pure science disclosures and technology push based value propositions relying on internal knowledge capabilities towards collaborative societal based technology disclosures which integrate external knowledge capabilities (Carayannis et al., 2012). As noted in university-industry research, ideally the move to collaborative disclosures should result in both technology and societal based innovations (with dual value propositions) with value co-created through the interaction and knowledge exchange between stakeholders (Carayannis and Campbell, 2009; Sobrero, 2013; Miller et al., 2014). Furthermore, from the literature, it is identified that these stakeholder interactions and knowledge exchange will result in an external knowledge capability (Caloghirou et al., 2004; Chesbrough, 2010), which replaces the predominant reliance upon internal knowledge capabilities evident within the TH based UTTBM. External knowledge capabilities are said to be imperative for innovation since they reflect the organisation's willingness and ability to absorb and integrate external knowledge in order to gain a competitive advantage (Kogut and 
Zander, 1992; Zahra and George, 2002; Chesbrough, 2003). The development of an external knowledge capability can form the basis of novelty and efficiency within an organisations business model design (Zott and Amit, 2010). Smith et al. (2005) identify that a knowledge capability depends on three types of resources; individual knowledge, relational contacts and an organisation's climate. However, it is noted by Perkmann et al. (2013) that the ability of a university to develop an external knowledge capability will depend not only on academics' intellectual capital but will also rely on internal norms, processes and organisational culture to influence external stakeholder engagement and relationship building (Perkmann et al., 2013).

Krucken (2003) identifies that the path dependent nature of universities often underpins their culture and norms. Within the UK, universities are often distinguished as being research intensive versus universities with a wider remit, with each of these university types having different organisational processes regarding career progression and perceived legitimacy of engaging in a range of knowledge transfer activities with external stakeholders beyond technology commercialisation, journal publications and research funding (O’Kane et al., 2015).

Within business model innovation research, knowledge exchange with stakeholders is deemed crucial in relation to future business model development (Zott et al., 2011; Miller et al., 2014) However, organisational culture is said to underpin the capabilities needed for business model change (Matzler et al., 2013; Hock et al., 2016). Indeed, Wirtz (2015:14) identifies the need to acknowledge “contextual differences between different business models as we're incapable to explain why certain models will function in particular environments and the others are not” illustrating the influence organisational factors may have on business models development. Furthermore, it is identified by Amit and Zott (2010) that past business models often shape future business model design highlighting the path dependent nature of business model development. So for example, the path dependent nature of universities often means that 
they find it difficult to adapt to external influences and instead attempt to interpret external influences to meet existing processes and mechanisms (Krucken, 2003).

It can be derived from literature that the ability of universities to integrate more fully with industry and ends users reflects a move from $\mathrm{TH}$ to $\mathrm{QH}$ structures however, path dependency and organisational culture and norms will impact upon universities' ability to transition into this new QH based UTTBM. Figure 1 graphically depicts these challenges facing universities.

[Insert Figure 1 around here]

As can been seen in Figure 1, the need to more fully embed industry and end users at all stages of the commercialisation process (Carayannis and Rakhmatullin 2014; Miller et al., 2014) reflects a move away from pure science disclosures and technology push based value propositions towards collaborative technology disclosures (Carayannis et al., 2012) which is depicted in the presentation of two competing business models. These two business models are competing for legitimacy and scarce resources where the ability to fully embrace QH structures demands changes to internal organisational processes to embed industry and end users throughout the university technology commercialisation process. However, as identified within the literature, path dependency will influence` organisational culture and norms which ultimately will impact on the ability to transition from a TH to a QH UTTBM. However, to date, little is known in relation to how and to what extent universities' path dependency will influence their ability to develop and adapt their business model in turbulent environments. This leads us to our first research question:

RQ1- How has the University’s organisational culture influenced its ability to engage QH stakeholders within its UTTBM design? 
Building on this, stakeholder knowledge exchange is said to be a key shaping factor on business model design (Zott and Amit, 2010; Zott et al., 2011). Hence, leads us to our second research question:

RQ2 - How has the UTTBM been shaped by QH stakeholder interactions and knowledge exchange in a path dependent manner?

\subsection{Research Methodology}

A qualitative methodology was deemed appropriate, given that business models in a university context is an under-researched phenomena (Gartner and Birley, 2002; Dana and Dana, 2005). A comparative case study approach was adopted which facilitated analysis across two different university types, which responds to calls by Edquist (2005) for comparative studies to aid theoretical and empirical advancement. Furthermore, universities of different types were chosen to facilitate the exploration of contextual differences which is currently lacking in entrepreneurship and innovation research (Wright 2014; Autio et al., 2014). Table 2 provides an overview of each university.

The research adopted a longitudinal perspective, consisting of data collection at multiple periods across a six year ${ }^{1}$ period. This helps alleviate limitations of existing business model research which often portrays a business model at a single point in time and thus fails to capture developmental aspects (Demil et al., 2015).

[Insert table 2 here]

Semi-structured interviews with purposeful heterogeneous stakeholders (Alvesson and Skoldberg, 2009) involved in each case university’s UTT process were collected in 2008; 2010; 2012; 2014. It should be noted that the TTO in both cases were intertwined within the two respective universities, thus whilst the TTOs had specific staff and strategic managers, their

\footnotetext{
${ }^{1}$ Six years was the current Research Excellence Framework (REF) cycle. REF is a framework used in the UK to assess the quality of research in Higher Education Institutions.
} 
activities aligned to the respective university's strategic mission. Appendix 1 provides an overview of the interviewees at each data collection point and provides the case codes of interviewees. Interviews lasted approximately 1-2 hours, with repeat interviews lasting between 30 minutes and 1 hour. A semi-structured interview guide was followed where each respondent was asked a series of questions regarding the development of their respective university UTT processes, challenges encountered with UTT commercialisation processes and external stakeholder engagement in UTT. In addition, company documentation consisting of innovation strategy documents, UTT procedure documents and online web material (shown in the Appendix) which were typically produced in "real time" served as a means of triangulation, thus counteracting any anomalies, preferential hindsight or retrospective memory bias that may have arisen during the interviewing process (Yin, 2011).

We made efforts to guarantee the trustworthiness of our data. First, we provided a traceable chain of evidence which increased validity and reliability and helped alleviate the limitations associated with case study research (Yin, 2011). Second, we continually sought to clarify and validate our analysis via repeat interviews with informants.

Data analysis took place both manually and through NVivo 10 to add systematic structure to the data due the longitudinal nature of the data collected (Bazeley, 2007). After each interview, reflections and preliminary patterns were recorded by the research team (Miles and Huberman, 1994). These were then converted into memos in NVivo. Cross referencing across initial and repeat interviews and secondary documentation facilitated a holistic picture to form in relation to the development of the UTTBM. An iterative and reflexive process to data analysis was followed whereby data was collected and interpreted through constant referral to literature to aid theory development (Yin, 2011).

Coding took place in three stages. First, a process of open inductive coding (Miles and Huberman, 1994) was carried out independently by two members of the research team. Regular 
meetings helped gain a consensus of the open codes. This resulted in 64 open codes spanning across the four data collection points. Next, a process of theoretical coding was conducted Glasier (1978) which involved cross-coding between researchers, with regular meetings to agree upon any variances in codes improving rigour and increased reliability and validity (Yin, 2011). This resulted in three overarching themes, namely Technology Disclosure, IP Policy and Organisational Culture (University Type). Table 3 outlines the coding process.

[Insert table 3 here]

\subsection{Findings}

\subsection{Technology Disclosure}

The technology disclosure process within the UTTBM experienced the most significant change as a result of the inclusion of industry and end users at the initial stages of the commercialisation process. At the start of the research period, it was evident from the interviews and document analysis that both universities' technology disclosure followed a traditional process, where the principal investigator (PI) (academic entrepreneur) filled in a disclosure form which was assessed by the commercialisation team drawing upon their experience and industry specific databases, with very little external commercial critique. Indeed, the TTO often relied solely upon internal knowledge capabilities with a lack of end user influence to determine technology potential. This caused a lot of frustration with PIs who felt that the commercialisation staff lacked the knowledge and skills to assess technologies from a wide spectrum of disciplines and niche areas, as Case 1 PI4 identifies "how can someone who is not an expert in my area know the commercial potential of this niche specialist market? We had to conduct the market research ourselves to convince the TTO before they would even let us proceed to speak with potential investors". Thus, it was evident in both cases that at the beginning of the research period, there was an over reliance on internal knowledge sources with limited engagement with end users reflecting the well-rehearsed critiques of a TH based 
UTTBM. The TTO staff in both universities stated that when technologies fell outside their remit, external experts from industry were sought. However, according to the PIs this appeared to be adhoc in nature.

In the repeat interviews, several developments to the UTTBM in both cases were identified which according to TTO staff was driven by both regional policy and University senior management. Accordingly, there was increasing pressure to prove the impact of research within society and to align research with societal needs, with funding increasingly dependent upon this stipulation. Case 2 TTOM identified "we now need to consider the impact of research from the very beginning of a technology disclosure with future changes to approval to research funding requiring the impact case to be cited before an application for research funding is even made». It was evident during the research period, that disclosure processes in both universities had become more streamlined yet flexible to allow for more collaborative disclosures, Accordingly, Intellectual Property issues were addressed resulting in changes to the disclosure process and the economic structure of the UTTBM allowing end users equity in the ownership of Intellectual Property. Both universities’ websites were redeveloped to facilitate more "user friendly” links where industry and potential end users could contact the University directly in order to become involved in the UTT process as co-creational partners (with industry often providing advice by sitting on boards of spinout companies and end users being involved throughout the commercialisation process). A member of Case 2's business liaison team noted that a seminar series had provided them with networking opportunities with a wide range of businesses thus resulting in a pool of accumulated expertise for them to draw upon. Case 2 also developed their UTTBM to include an open access portfolio of IP which end users could access with the potential of trialling a particular technology for free, subject to conditions. These developments signalled an attempt to develop external knowledge capabilities in the UTTBM. 
Comparatively, Case 1 also implemented additional activities, which although not directly related to the UTTBM, were aimed at developing collaborative relationships with industry and end users, such as the Chief Executives Club, Industry Advisory Boards, and specialised research centres within each of the disciplines. However, these activities appeared to exist in silos, particularly at a school level with a lack of interdisciplinary interaction and collaboration across faculties. Thus, there was an absence of effective knowledge sharing mechanisms across activities required to capture these external knowledge capabilities at a school and faculty level to be utilised in the UTTBM.

At the beginning of the research period, PIs and TTO staff in Case 2 identified that the TH based UTTBM lacked flexibility to allow technologies which did not lend themselves to be protected in the traditional way i.e. patents to progress. However, in the repeat interviews, it was identified that Case 2 had developed their UTTBM to provide alternative processes for technologies to be disclosed in the art and creative industries. Case 2's TTO manager identified that they were seeing more instances of ideas being disclosed in collaboration with end users leading to shared value creation for all stakeholders. This was echoed by the PIs who had expressed their frustration in the initial interviews with the required non-disclosure agreement protocol prior to sharing ideas with potential industrial partners. The use of NDAs reflected their previous closed approach which was heavily reliant upon standardised linear processes which limited the development of “outside in” knowledge capabilities.

In comparison, whilst Case 1's disclosure process was streamlined, it did not change significantly over the period of research. However, it was reported by TTO staff that there was a gradual increase in the number of collaborative disclosures between academics, and end users. Case 1 TTO commercialisation executive identified that the attitude and motivation of the PIs towards developing networks with industry and end users was a core barrier to developing to a QH based UTTBM. Furthermore, PI1 in Case 1 commented "There is a lot of bureaucracy 
within a university in addition to the cultural aspect. In a research intensive university many academics want to just focus on their research". Further investigation, revealed the tensions relating to the 'publish or patent dilemma' imposed as a result of internal performance mechanisms which emphasised publication outputs due to Case 1 being a research intensive university. Furthermore, it was identified that limited TTO resources meant that the transition to a QH UTTBM was largely dependent upon PIs and schools developing external knowledge capabilities. 'We pick up what's already developed. It would be nice to have the resources to go and make those connections' (Case 1 TTO commercialisation executive). Thus, internal norms regarding engaging in networking and knowledge transfer appeared to impact upon motivation of academics and thus the ability to fully integrate end users into the UTTBM.

\subsection{IP Policy Development}

Another development which emerged over the research period in Case 2 was the development of an open IP policy whereby industry could use certain technologies for a period of time before committing to purchase/licence. This was aimed at bridging “inside-out" and “outside-in” knowledge flows by opening up their UTT process to embrace more co-creational value creation and transfer with end users. Case 2 TTO manager suggested that often end users were deterred from getting involved in early stage technologies due to the high levels of risk involved, 'It is a bit like try before you buy. There are obviously conditions attached but I think it helps foster trust and builds relationships'. Case 2 TTO commercialisation executive anticipated that this policy would not only lead to greater engagement with end users at the commercialisation stage but also would have a cumulative effect and lead to external knowledge capabilities which could be utilised throughout the whole UTT process. Furthermore, it was hoped that a more open IP policy would help overcome some of the historical tensions relating to IP valuation aiding the development of trusting relationships at earlier stages of the UTT process. 
Whilst Case 1 did not have an open IP policy in place, it was identified that this was something they were considering as a result of the potential value of research impact case studies. A TTO in Case 1 stressed that an open IP policy would have to be managed carefully to ensure technologies with commercial potential were financially viable for the university. However, the common consensus was such a policy would facilitate relationship building with key industry players and end users which could then be leveraged in the future.

Finally, at the end of the research period, it was identified by Case 2 TTO manager that Case 2 was undergoing a period of strategic restructuring within the university, with the amalgamation of the Research and Enterprise Office and the Office for Innovation (which dealt with technology commercialisation activity and where the TTO was located). The key driver behind this was the need to develop more integrated links between research activities and their impact for industry and wider society, thus facilitating the simultaneous achievement of technology and societal based value propositions within the UTTBM. Whilst this was in the early stages, Case 2 research and enterprise strategic staff member suggested this had the potential to make significant changes to the UTTBM as it would entail industry and end users being involved in the early stages of a funding proposal, before the actual disclosure of a technology. It was anticipated that this would enable the university to build a diverse external knowledge base to draw upon to ensure societal impact and so result in the co-creational development of technologies during UTT. In contrast, Case 1's Research and Enterprise Office and TTO were already located in the same building however, they still appeared to operate in silos, with conflicting performance mechanisms.

It was evident that Case 2 experienced several developments to their UTTBM over the research period which represented the shaping influence greater involvement of end users and industry had on their UTTBM activities. Similarly, there was evidence that Case 1's UTTBM had also developed by incorporating more end-user involvement, however these developments 
were less extensive. Case 2 appeared to take a proactive stance in implementing more cocreational activities whereas Case 1 appeared to be slower to adopt end user initiatives due to greater path dependency and organisational inertia which was thought to be as a result of the traditional research culture of the university which is discussed further in the next section.

\subsection{Influence of Organisational Culture (University Type)}

As illustrated in Table 2 the differences in the profile of the two case universities is evident. The interviews revealed the influence of organisational culture as underpinned by the universities strategic direction, on the PIs' willingness and ability to engage more collaboratively and openly with end users; thus resulting in variances in how their respective UTTBMs developed and changed over the research period. Within Case 1, academic promotional mechanisms were said to be dependent upon publications and research income whereas Case 2 had multiple routes to promotion which included any combination of two streams namely, teaching, research, academic enterprise and UTT. In Case 1, both the PIs and TTO staff identified the misalignment between the internal promotional mechanisms and the need to engage in more co-creational collaborative interactions to facilitate transition to a $\mathrm{QH}$ model. As Case 1 PI 2 identifies “we are ultimately measured against the number of high quality publications we have and how much research income we can generate. Whilst engagement with industry can sometimes benefit these activities, the opportunity cost of networking with industry which may not generate any research is often too great”. This illustrates a disconnect between the university strategy and the need to implement changes to the UTTBM. These internal mechanisms appeared to limit the ability to develop an external knowledge capability since many academics felt it was not within their core remit. Case 2 BL1 appeared to have contrasting views stressing the importance of industry engagement within the university. However, all the PIs emphasised that the requirements at a faculty level emphasised research publications over 
industry engagement activities. 'Whilst industry engagement and technology transfer is important... I need to reach my quota regarding publications each year' (Case 1 PI3).

However, it was noted that emphasis on high quality international research did sometimes aid the formation of relationships with industry and end users. Case 1 PI2 who at the latter stages of the research period formed a spin out company in medicinal chemistry identified: 'They (an industry player) seen an article that we had published in a top journal in our field and got in contact saying they were interested in funding further research. We have now been working with them over the past year and they have funded future research' (Case 1 PI2). Despite this, historical and internal norms which gave emphasis to research publication activity in Case 1 led to path-dependent behaviour and did appear to limit development into a QH based UTTBM. It was recognised that changes to the Research Exercise Framework (REF) which now includes impact, may enhance the legitimacy of UTT and lead to industry and end users further shaping the design of the UTTBM. However, Case 1 TTO1 suggested that the additional measures of impact within the REF will not necessarily translate to more cocreational UTT commercialisation and instead could lead to other forms of knowledge transfer with industry with academic outputs such as publications and reports. For example, it was identified that an impact research case study often derives greater financial rewards in higher education funding and less risk for academics than pursuing the commercialisation route. Therefore, Case 1's TTO appeared to continuously encounter challenges in enforcing the legitimacy of developing activities and processes to facilitate changes to the UTTBM to meet regional innovation policy requirements.

In contrast, Case 2's internal culture did not appear to limit UTTBM development to incorporate end users in the same manner. It was identified by all stakeholders, in particular government, that even from the beginning of the research period, Case 2 had a greater external knowledge capability compared to Case 1. 'I think XX (Case 1) has a very strong research base 
whereas XX (Case 2) have very strong industry engagement. This is not a negative thing for any of the universities since both complement the region' (Government commercialisation executive). The multiple routes to promotion in Case 2 meant that the university had a stronger external knowledge base to build upon to facilitate the implementing more collaborative UTT practices with end users. Case 2 TTO manager identified that the strength of already existing relationships with industry and end users aided their ability to respond to recent innovation policy. Furthermore, since academic enterprise and UTT were deemed legitimate routes to promotion, academics within Case 2 were allocated more time to engage in external knowledge transfer activities which helped to build up a wider external resource base to be utilised during UTT.

\subsection{Discussion}

From the analysis of the findings, three critical themes emerged which aided understanding of the changes within the two cases UTTBMs over the six year research period. Based on the findings, the initial framework has been refined to depict the complexity of the transition from a TH based UTTBM towards a QH based UTTBM. This new figure is presented in Figure 2 with the changes to this model discussed below.

[Insert figure 2 here]

The findings concurred with previous research (Krucken, 2003; Howell and Annansingh, 2013) and identified that the path dependent nature of the two universities impacted their ability develop their respective UTTBMs. It was found that organisational culture, which underpinned the university remit and internal processes, influenced PI motivation and perceived legitimacy of engaging with industry and end users (as reflected in Figure 2 as mediating the reliance on internal versus eternal knowledge capabilities). This in 
turn influenced initiatives facilitating the engagement with industry and end users thus affecting their ability to develop the UTTBM.

It was apparent that both universities exhibited a TH based UTTBM at the beginning of the research period, where technology disclosure was largely a closed process with an overreliance on internal knowledge sources. Indeed, concurring with Carayannis and Campbell, (2009) this resulted in university, government and industry playing prescribed roles at key junctures of the UTT process with limited co-creational knowledge sharing or capture, resulting in a relatively closed TH based UTTBM. Case 2 did show evidence of some industry engagement from the beginning of the research period which was facilitated by the legitimacy of academic enterprise as a route to promotion. This aided the development of industry relationships however, Case 2's internal UTT processes were not sufficiently developed at this stage to take advantage of this external knowledge base (Perkmann and Walsh, 2007; Perkmann et al. 2013).

As the research period progressed, there was evidence of inside-out and outside-in knowledge exchange (Chesbrough, 2007; 2010). This was seen through the development of both case Universities’ UTTBM incorporating more open activities reflecting the shaping influence regional government, industry and end users had on the UTTBM (Bosch-Sijtema and Bosch, 2015). Indeed, both cases implemented a wide range of adjustments to their UTTBM to facilitate more open and collaborative integration of stakeholders (Arnkil et al., 2010). However, it was evident that Case 2 was more advanced in their UTTBM development, where effort was made to collaborate and develop relationships with industry and end users at key junctures before the UTT process even commenced, thus establishing an external knowledge base to be utilised at a later date (Perkmann and Walsh, 2007). Whilst Case 1 did report a marginal increase in collaborative disclosures with industry and end users during the research period, it was identified that the majority of disclosures still resonated from pure research 
signalling path dependent behaviour and an over reliance on internal knowledge sources (Teece, 2010). This constituted a 'lock in' with respect to Case 1's UTTBM design (Zott and Amit, 2010) where prior internal structures and norms within the university were impacting upon the ability to make subsequent changes throughout the UTTBM. This extends research highlighting the path-dependent behaviour of business model development (Spieth et al., 2014; Da Silva and Trkman, 2014) and identifies the historical challenges universities need to overcome to develop their UTTBMs.

At the end of the research period, it was evident that both universities were in a state of disequilibrium and had slowly transitioned their UTTBM to a point where they were exhibiting a hybrid UTTBM where they were exhibiting elements of both a TH based UTTBM and QH based UTTBM simultaneously. This can be seen in the revised model presented in Figure 2 where the institutional logics of both business models were evident. It should be noted that hybridity is not always a negative, with past studies identifying organisations having multiple revenue streams within their business model (Hahn and Spieth, 2014; Santos et al., 2015) or running several business models in tandem (Casadesus-Masanell and Tarzijan, 2012). In the case of the two universities, the hybridity appears to have caused a permanent disequilibrium (Demil and Lecocq, 2015) where both case universities business models appeared to be facing challenges in relation to the allocation of scarce resources and confusion over perceived conflicting remits of academics. This was causing inefficiencies and impacted upon the willingness and motivation of PIs to engage more fully with industry and end users impacting the effectiveness of attempts to transition to a QH UTTBM. Pache and Santos (2013) identify that competing institutional logics within a hybrid organisation can cause challenges for staff where they may choose to ignore, comply, resist (or do a combination) institutional change. It was evident that tensions also existed between the PIs and TTO, with both of these internal stakeholders reporting resource limitations. Demil and Lecoq (2015) identify that permanent 
disequilibrium presents opportunities for organisations to exploit resources and offer new value propositions. In the context of the two cases, it was evident that changes need to be made to existing performance mechanisms and processes in order to transition completely to a QH UTTBM. Therefore, both universities will need to re-evaluate their resource allocation in order to allow for greater engagement with industry and end users.

Furthermore, it was evident that to facilitate the successful development of the UTTBM alignment is needed with other business models within both universities (teaching research and academic enterprise business models). Alignment with these other business models would help with resource allocation thus reducing the resistance of PIs to engage with external stakeholders and so help manage the disequilibrium. It was evident that there was a need for knowledge to be shared across business models, utilising boundary spanners to develop both efficiencies and joint value creation in order to fully embrace QH engagement which required 'buy in' from all areas of the university. This concurs with research by Huyghe et al. (2014) where boundary spanning activity was thought to help manage the hybridity of the emergent UTTBM. However, in Case 1 there appeared to be a misalignment where industry engagement activities at a school level was not being captured and translated into knowledge capabilities which could be utilised in the UTTBM due to a lack of co-ordination between each of the departments.

\subsection{Conclusion}

This aim of this paper was to explore how the need to more fully engage with industry and end users, reflecting a move to QH structures has influenced the UTTBM. As a result of our empirical findings, we propose a refined conceptual framework which depicts a hybrid UTTBM.

In relation to the research questions, it is evident that over the research period both universities attempted to implement activities aimed at industry and end user engagement. However, attempts to progress both cases UTTBMs from a TH based UTTBM to a QH based 
UTTBM was limited by path dependent behaviour where the internal culture which reflected the academic remit, performance mechanisms and norms regarding academic engagement with industry and end users appeared to dictate the legitimacy of changes to the UTTBM (CasadesusMasanell and Ricart, 2010; Howell and Annansingh, 2013; Hock et al., 2016) and the resources allocated to developing an external knowledge capability (Chesbrough, 2007: 2010; Perkmann et al., 2013). The integration of existing and emergent changes in the UTTBM where government, industry and end users had competing goals led to fluctuations within the UTTBM which took on features of the traditional TH based UTTBM and the emergent QH based UTTBM causing a permanent state of disequilibrium (reflected in Figure 2). This disequilibrium caused challenges in relation to the allocation of scarce resources and motivations of academics to engage more fully with industry and end users. Furthermore, the complexity of the hybrid UTTBM was enhanced due to apparent need for interdependency between the UTTBM and business models relating to teaching, research and academic enterprise within the two universities.

Accordingly, we contribute to the business model literature by providing a more nuanced understanding of the complexity of changing business models within the university context. In particular, we contribute to the limited body of research on the existence of hybrid business models (Huyghe et al., 2014; Hahn and Spieth, 2014) by revealing how a hybrid business model can emerge involuntarily within universities as a result of a need to engage more fully with QH stakeholders who often have conflicting goals and objectives causing competing institutional logics. We offer exploratory insights into the realities of permanent disequilibrium within business models which causes challenges for resource allocation. We also extend research on the path dependent nature of business model development where organisational culture and norms impact the ability to develop an organisation's business model. 
There are several implications which arise from this research for those working within the field of UTT as advisors and policy makers. Accordingly, this paper draws attention to the difficulties encountered in relation to greater industry and end user engagement within a university context and the implications of such on micro level activities when competing value propositions strive for legitimacy and scarce resources (Arnkil et al., 2010). Consequently, this research identifies the need for innovation policy to consider the organisational context which will reflect variances in the level of industry and end user engagement across universities and subsequent impact on their business models.

Whilst this research adopted a comparative case study methodology, it should be noted that our aim was analytical as opposed to empirical generalization (Yin, 2011). In addition to this, our longitudinal perspective addressed the static view of business models which currently dominates the literature (Demil et al., 2015). To conclude, we suggest a number of future research avenues which forms the basis of a research agenda. Our findings provide evidence of the influence of culture which impacted upon business model development. Thus, future research should explore how organisations can overcome path-dependency and associated cultural norms and develop learning capabilities to facilitate changes in a business model. Building on this, future research should also explore how engagement with industry and end users can be aligned with internal performance mechanisms to help facilitate the development of the UTTBM. Given the insights provided into the fluctuations prevalent within the university business models, signalling hybridity, more research is required on the transitional and permanent disequilibrium states instigated as a result of this hybridity and the impact of such on business model design issues and implementation. It is evident that UTTBMs are undergoing a process of experimentation; therefore, opportunities exist to operationalize our conceptual framework by statistically testing relationships between university type, QH engagement, PI motivations and innovation activities. Furthermore, research should explore the 
interdependency of the various business models within a university remit (i.e. teaching, research, academic enterprise technology transfer) and the challenges of aligning multiple business models often with varying value propositions and revenue models.

\subsection{References}

Alvesson, M. and Skoldberg, K. (2009) Reflexive methodology-new vistas for qualitative research. London: Sage.

Arnkil, R., Järvensivu, A., Koski, P., and Piirainen, T. (2010) Exploring Quadruple Helix Outlining user-oriented innovation models. University of Tampere, Institute for Social Research, Work Research Centre.

Autio, E., Kenney, M., Mustar, P., Siegel, D., and Wright, M. (2014) Entrepreneurial innovation: The importance of context. Research Policy, 43, 7, 1097-1108.

Bazeley, P. 2007. Qualitative Data Analysis with NVivo. Sage: London.

Bosch-Sijtsema, P., and J. Bosch. 2015. User Involvement throughout the Innovation Process in High-Tech Industries. Journal of Product Innovation Management, 32, 5, 793-807.

Caloghuriou, Y., Kastlli, I., and Tsakanikas, A. (2014) Internal capabilities and external knowledge sources: complements or substitutes for innovative performance? Technovation, 24, 1, 29-39.

Carayannis, E.G., Barth, R.D., and Campbell, D.F.J. (2012) The quinuple helix innovation model: global warming as a challenge and driver for innovation. Journal of Innovation and Entrepreneurship, 1, 1, 1-12.

Carayannis, E.G., and Campbell, D.F.J. (2009) “Mode 3” and “Quadruple Helix”: toward a 21st century fractal innovation ecosystem. International Journal of Technology Management, 46 3/4, 201-234.

Carayannis, E. G., and Rakhmatullin, R. (2014) The Quadruple/Quintuple innovation helixes and Smart Specialisation Strategies for sustainable and inclusive growth in Europe and beyond. Journal of the Knowledge Economy, 5, 2, 212-239.

Casadesus-Masanell, R., and Ricart, J.E. (2010) From strategy to business models and on to tactics. Long Range Planning, 43, 2-3, 195-215.

Casadesus-Masanell. R., and Tarijan, J. (2012) When one business model isn't enough. Harvard Business Review, 90, 1-2.

Chesbrough, H. (2003) Open Innovation: The new imperative for creating and profiting from technology, Harvard Business School Press. 
Chesbrough, H. (2007) Why companies should have open business models. MIT Sloan Management Review, 48, 22-28.

Chesbrough, H. (2010) Business model innovation: Opportunities and barriers. Long Range Planning, 43, 354-363.

Dana, L.P. and Dana, T.E. (2005) Expanding the scope of methodologies used in entrepreneurship research. International Journal of Entrepreneurship and Small Business, 2, 1, 79-88.

Da Silva, C.M. and Trkman, P. (2014) Business model: What it is and what it is not. Long Range Planning, 47, 6, 379-389.

Demil, B., Lecocq, X., Ricart, J.E., and Zott, C. (2015) Introduction to the SEJ Special Issue on Business Models: Business Models within the Domain of Strategic Entrepreneurship. Strategic Entrepreneurship Journal, 9, 1, 1-11.

Demil, B. and Lecocq, X. (2010) Business model evolution: In search of dynamic consistency. Long Range Planning, 43, 2-3, 227-246.

Edquist, C. (2005) Systems of innovation: Perspectives and challenges, in: Fagerberg, J., Mowery, D., and Nelson, R. (Eds.) Oxford Handbook of Innovation, UK, Oxford University Press, 181-208.

Furr, N. (2016) Hybrid business models look ugly but they work. Harvard Business Review, March.

Gartner, W.B. and Birley, S. (2002) Introduction to the special issue on qualitative methods in entrepreneurship research. Journal of Business Venturing, 12, 5, 387-396.

Gaus, O. and Raith, M.G. (2016) Commercial transfer: A business model innovation of the Entrepreneurial University. Industry and Higher Education, 30, 3, 103-201.

Gephart, R. P. (1986) Deconstructing the defense for quantification in social science: A content analysis of journal articles on the parametric strategy. Qualitative Sociology, 9, 2, 126-144.

Glasier, R. G. (1978) Theoretical sensitivity. Mill Valley, CA:Sociology Press.

Hahn, R., and Spieth, P. (2014) Business Model Design for Sustainability - The Case of Hybrid Business Models. Paper presented at ISPIM Conference, Dublin.

Hock, M., Clauss, T., and Schultz, E. (2016) The impact of organisational culture on the firms capability to innovate the business model. R\&D Management, 46, 3, 433-450.

Hodges, R. A., and Dubb, S. (2012) The Road Half Traveled: University Engagement at a Crossroads. East Lansing: Michigan State University Press.

Howell, K.E. and Annansingh, F. (2013) Knowledge generation and sharing in UK universities: a tale of two cultures? International Journal of Information Management, 33, 1, 32-39. 
Huyghe, A., Knockaert, M., Wright, M., and Piva, E. (2014) Technology transfer offices as boundary spanners in the pre-spin-off process: the case of a hybrid model, Small Business Economics, 43, 289-307.

Kogut, B. and Zander, U. (1992) Knowledge of the Firm, Combinative Capabilities and the Replication of Technology. Organization Science, 3, 3, 383-397.

Krucken, G. (2003) Learning the 'New, New Thing': On the role of path dependency in university structures. Higher Education, 46, 315-339.

Matzler, K., Bailom, F., Friedruch von den Eichen, S., and Kohler, T. (2013) Business model innovation: Coffee triumphs for Nespresso. Journal of Business Strategy, 34, 2, 30-37.

Miles, M. B. and Huberman, A.M. (1994) Qualitative data analysis, $2^{\text {nd }}$ edition. Sage Publishing, Thousand Oaks.

Miller, K., McAdam, M., and McAdam, R., (2014) The changing university business model: A stakeholder perspective. $R \& D$ Management, 44, 3, 265-287.

O;Kane, C. Mangematin, V., Geoghegan, W., and Fitzgerald, C. (2015) University Technology Transfer Offices: The search for identity to build legitimacy, Research Policy, 44, 2, 421-437.

Pache, A.P. and Santos, F. (2013) Inside the Hybrid Organization: Selective Coupling as a Response to Competing Institutional Logics. Academy of Management Journal, 56, 9721001.

Pache, A. C. and Santos, F. (2010) When worlds collide: The internal dynamics of organizational responses to conflicting institutional demands. Academy of Management Review, 35: 455-476.

Perkmann, M., and Walsh, K. (2007) University-industry relationships and open innovation: towards a research agenda. International Journal of Management Reviews, 9, 4, 259-280. Perkmann, M., Tartari, V., McKelvey, M., Autio, E., Brostrom, A., D’Este, P., Fini, R., Geuna, A., Grimaldi, R., Hughes, A., Krabel, S., Kitson, M., Llerena, P., Lissoni, F., Salter, A., and Sobrero, M. (2013) Academic engagement and commercialisation: A review of the literature on unicersity-industry relations. Research Policy, 42, 423-442.

Pratt, M.G. and Foreman, P.O. (2000) Classifying managerial responses to multiple organizational identities. Academy of Management Review, 25, 1, 18-42.

Santos, F., Pache, A.C., and Birkholz, C. (2015) Making Hybrids Work: Aligning Business Models and Organizational Design for Social Enterprises. California Management Review, 57, 3, 36-58. 
Smith, K.G., Collins, C.J., and Clark, K.D. (2005) Existing knowledge, knowledge creation capability and the rate of new production introduction in high technology firms. Academy of Management Journal, 48, 2, 740-751.

Sobrero, M. (2013) Academic engagement and commercialisation: A review of the literature on university Industry relations. Research Policy, 42, 2, 423-442.

Spieth, P., Schneckenberg, D., and Ricart, J.E. (2014) Business model innovation: State of the art and future challenges for the field. $R \& D$ Management, 44, 3, 237-247.

Teece, D.J. (2010) Business models, business strategy and innovation. Long Range Planning, 43, $172-194$.

Voss, Z. G., Cable, D.M., and Voss, G.B. (2006) Organizational identity and firm performance: What happens when leaders disagree about “who we are?” Organization Science, 17, 6, 741755.

Wirtz, B. W., Pistoia, A., Ullrich, S., and Gottel, V. (2016) Business models: Origins, development and future research perspectives. Long Range Planning, 49, 1, 36-54.

Wright, M. (2014) Academic entrepreneurship, technology transfer and society: Where next? Journal of Technology Transfer, 39, 322-334.

Yin, R.K. (2011) Case study research: Design and methods (4th ed). Thousand Oaks, CA: Sage.

Zahra, S.A. and George, G. (2002) Absorptive Capacity: A review, reconceptualization and extension. The Academy of Management Review, 27, 2, 185-203.

Zott, C. and Amit, R. (2010) Business model design: An Activity System Perspective. Long Range Planning, 49, 216-226.

Zott, C., Amit, R., and Massa, L. (2011) The business model: recent developments and future research. Journal of Management, 3, 1019-1 


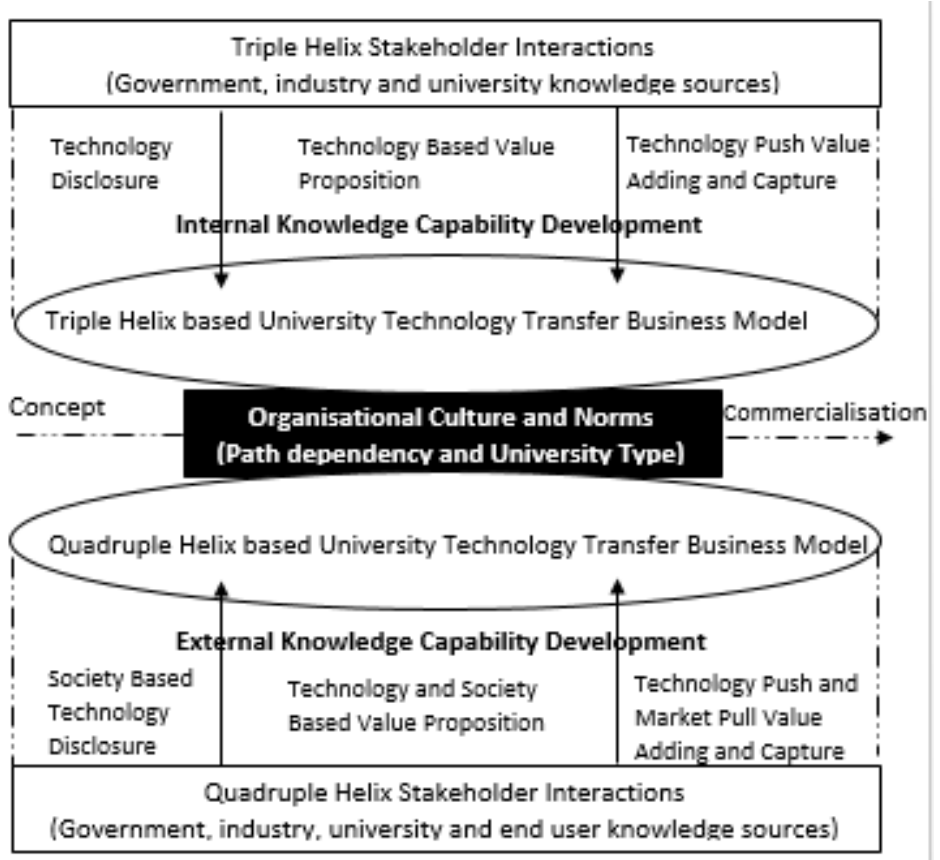

Figure 1: Initial Conceptual Framework

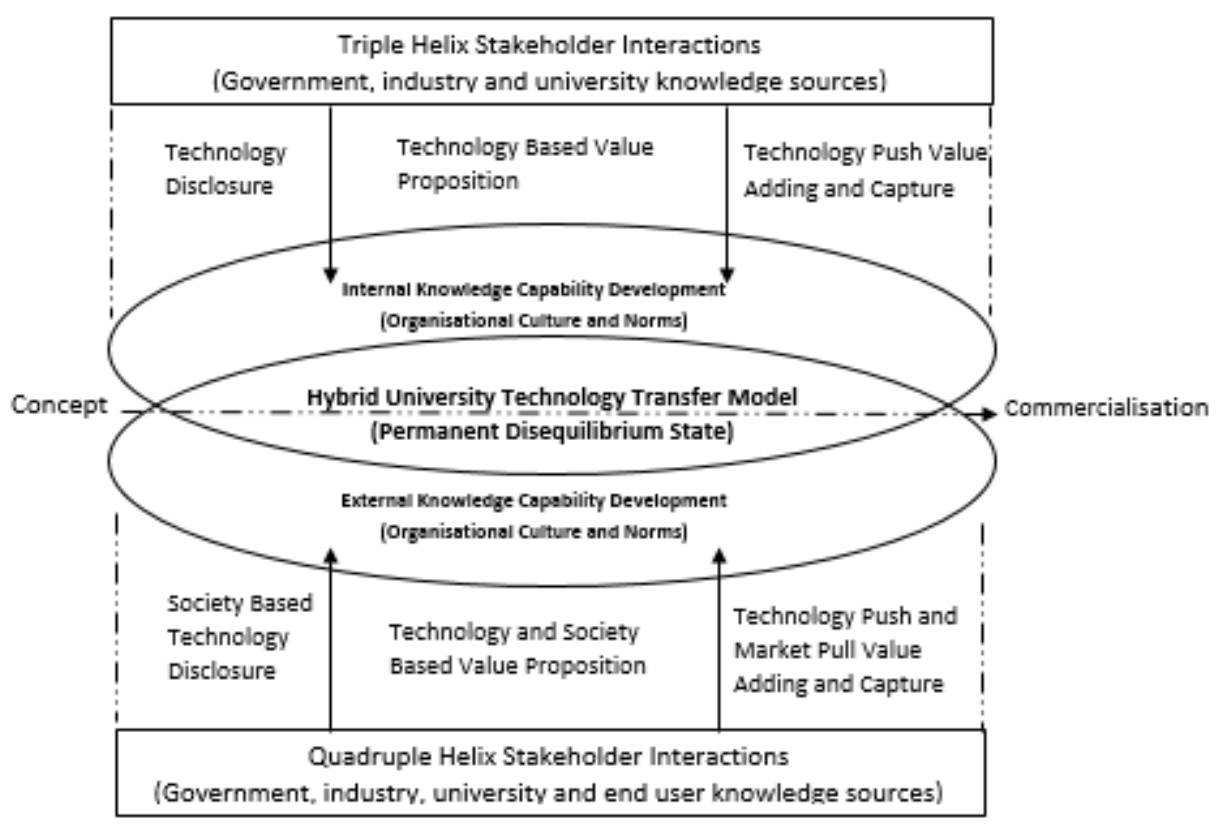

Figure 2: Refined framework 
Table 1 - Summary of hybrid organisation theory bases

\begin{tabular}{|c|c|}
\hline Main theoretical approach and dimensions & References \\
\hline $\begin{array}{l}\text { Business Model theory } \\
\text { - } \quad \text { Plural and Hybrid Business Models } \\
\text { - } \quad \text { Strategic choice and evolving Business } \\
\text { Models } \\
\text { - } \quad \text { Business Model and organisational design } \\
\text { - } \quad \text { Business model Innovation } \\
\end{array}$ & $\begin{array}{l}\text { Casadesus-Masanell and Tarzijan (2012); Haigh et al. } \\
\text { (2015); Santos et al. (2015); Demil et al. (2015); } \\
\text { Wirtz et al. (2016); Huyghe et al. (2014); Hahn and } \\
\text { Spieth (2014). }\end{array}$ \\
\hline $\begin{aligned} & \text { Institutional theory } \\
&- \text { Strategic choice } \\
&- \text { Stakeholder theory } \\
&- \text { Legitimacy } \\
&- \text { Institutional pluralism and competing } \\
& \text { Institutional logics } \\
&\end{aligned}$ & Pache and Santos (2010); Pache and Santos (2013). \\
\hline $\begin{array}{l}\text { Organisation behaviour theory } \\
\text { - Identity theory and multiple organisational } \\
\text { identities and conceptions } \\
\text { - Multiple identities, legitimacy and } \\
\text { performance }\end{array}$ & Pratt and Foreman (2000); Voss et al. (2006) \\
\hline
\end{tabular}

Table 2: Profile of Case Universities

\begin{tabular}{|c|c|c|}
\hline & Case 1 & Case 2 \\
\hline Age & Established in 1908 & Established in 1994 \\
\hline Grouping & Russell Group & Universities UK \\
\hline Focus & $\begin{array}{l}\text { Research led and research } \\
\text { intensive where excellence in } \\
\text { research is seen as the lead driver } \\
\text { of the University in other areas }\end{array}$ & $\begin{array}{l}\text { Emphasis on a broad three strand } \\
\text { contribution based on teaching and } \\
\text { learning, research and academic } \\
\text { enterprise }\end{array}$ \\
\hline Aims & $\begin{array}{l}\text { Centres of excellence for basic } \\
\text { and applied research to entrain } \\
\text { funding and to inform teaching } \\
\text { and learning and academic } \\
\text { enterprise }\end{array}$ & $\begin{array}{l}\text { Emphasis on increased inclusivity } \\
\text { through a broad teaching and } \\
\text { learning provision with an applied } \\
\text { academic enterprise agenda } \\
\text { supported by applied research in } \\
\text { specific STEM fields }\end{array}$ \\
\hline $\begin{array}{l}\text { Academic staff } \\
\text { pathways }\end{array}$ & $\begin{array}{l}\text { Career progression and rewards } \\
\text { and recognition for academic } \\
\text { staff is based on REF criteria in } \\
\text { terms of research based } \\
\text { publications (typically } 12 \text { staff } \\
\text { plus for most disciplines). } \\
\text { Academic enterprise is viewed as } \\
\text { an additional activity alongside } \\
\text { teaching and learning. }\end{array}$ & $\begin{array}{l}\text { Academics Staff are encouraged to } \\
\text { major on two of the three career } \\
\text { path routes: academic enterprise, } \\
\text { research and teaching and learning. } \\
\text { Those including academic enterprise } \\
\text { are requested to engage in a wide } \\
\text { range of funding activities (KTP's, } \\
\text { University Technology Transfer, } \\
\text { Innovation Vouchers). }\end{array}$ \\
\hline $\begin{array}{l}\text { Current student } \\
\text { numbers }\end{array}$ & Circa 25,000 & Circa 25,000 \\
\hline Campus & Single Campus & Multi Campus $(n=4)$ \\
\hline $\begin{array}{l}\text { Undergraduate fees- } \\
\text { set by regional } \\
\text { government for both } \\
\text { universities }\end{array}$ & $f 3,575$ & $f 3,575$ \\
\hline $\begin{array}{l}\text { Non-student fee } \\
\text { funding }\end{array}$ & $\begin{array}{l}\text { Primary emphasis on UK Research } \\
\text { Council funding with a secondary } \\
\text { focus on EU funding (E.g. FP7 and } \\
\text { Horizon 2020) }\end{array}$ & $\begin{array}{l}\text { Emphasis on applied funding from } \\
\text { academic enterprise and applied } \\
\text { research activities and Research } \\
\text { Council funding in specific STEM } \\
\text { disciplines. }\end{array}$ \\
\hline $\begin{array}{l}\text { Academic enterprise } \\
\text { strategy }\end{array}$ & $\begin{array}{l}\text { - Activities in support of research } \\
\text { - Focus on University Technology } \\
\text { Transfer activities in support of } \\
\text { the research agenda } \\
\text { - An emphasis on entraining } \\
\text { organisations based on spin-off } \\
\text { activities }\end{array}$ & $\begin{array}{l}\text { - Academic pathway } \\
\text { - Emphasis on University } \\
\text { Technology Transfer funding to be } \\
\text { self-sustaining } \\
\text { - An emphasis on engagement with } \\
\text { local SME engagement }\end{array}$ \\
\hline
\end{tabular}


Table 3: Coding Scheme

\begin{tabular}{|c|c|c|c|}
\hline Open Codes & Key Themes & Open Codes & Key Themes \\
\hline $\begin{array}{l}\text { Collaborative digclosure } \\
\text { Academic disclosure } \\
\text { Intellectual property issues } \\
\text { Industry collaboration } \\
\text { Industry advisory boards } \\
\text { Industry gectors } \\
\text { Website development } \\
\text { Role of IP } \\
\text { Patents, copyrights and protection } \\
\text { NDA agreements } \\
\text { Disclosure process } \\
\text { Disclosure form } \\
\text { Patent or publigh } \\
\text { Knowledge club seminar series } \\
\text { Open access portfolio } \\
\text { External knowledge capability } \\
\text { End user co-creation } \\
\text { Stakeholder power }\end{array}$ & $\begin{array}{l}\text { Technology } \\
\text { Disclosure }\end{array}$ & $\begin{array}{l}\text { Academic remit } \\
\text { PI motivation } \\
\text { Strategic direction } \\
\text { Academic performance } \\
\text { mechanigms } \\
\text { Academic promotional mechanisms } \\
\text { Faculty/gchool } \\
\text { Research exercise framework } \\
\text { Organisational culture } \\
\text { Internal culture } \\
\text { Resource constraints } \\
\text { Disciplines } \\
\text { New versus red brick university } \\
\text { Governance } \\
\text { PI wiling to engage } \\
\text { Patent of publigh } \\
\text { Flexible routes to promotion } \\
\text { Business liaison } \\
\text { Interconnectivity of knowledge } \\
\text { transfer activities } \\
\text { Different value propositions } \\
\text { Stakeholder salience } \\
\text { Conflicting stakeholder demands } \\
\text { Networked buginess model }\end{array}$ & $\begin{array}{l}\text { Organisational } \\
\text { Culture } \\
\text { (University } \\
\text { Type) }\end{array}$ \\
\hline $\begin{array}{l}\text { Co-creational value propositions } \\
\text { Open IP policy } \\
\text { Historical tensions } \\
\text { IP valuation } \\
\text { Impact case studies } \\
\text { Financially viability } \\
\text { Organisational inertia } \\
\text { Traditional research culture } \\
\text { Knowledge flows } \\
\text { End user involvement } \\
\text { Establishing trust } \\
\text { Risk minimising strategies } \\
\text { Diverse external knowledge base } \\
\text { Technology based value } \\
\text { propositions } \\
\text { Societal based value propositions } \\
\text { Competing stakeholder goals }\end{array}$ & \begin{tabular}{|l|} 
IP Policy \\
\end{tabular} & & \\
\hline
\end{tabular}




\section{Appendix}

\begin{tabular}{|c|c|c|c|c|c|c|}
\hline \multirow[t]{2}{*}{ Interviewee } & \multirow[t]{2}{*}{ Case } & Codes & \multicolumn{4}{|c|}{ Year of Interview } \\
\hline & & & 2008 & 2010 & 2012 & 2014 \\
\hline Principal Investigator & 1 & Case 1 PI1 & $\mathrm{x}$ & $\mathrm{x}$ & $\mathrm{x}$ & $\mathrm{x}$ \\
\hline Principal Investigator & 1 & Case 1 PI2 & $\mathrm{x}$ & & & $\mathrm{x}$ \\
\hline Principal Investigator & 1 & Case 1 PI3 & $\mathrm{x}$ & $\mathrm{x}$ & $\mathrm{x}$ & $\mathrm{x}$ \\
\hline Principal Investigator & 1 & Case 1 PI4 & $\mathrm{x}$ & $\mathrm{x}$ & $\mathrm{x}$ & $\mathrm{x}$ \\
\hline Principal Investigator & 1 & Case 1 PI5 & $\mathrm{x}$ & & $\mathrm{x}$ & $\mathrm{x}$ \\
\hline Principal Investigator & 2 & Case 2 PII & $\mathrm{x}$ & & & $\mathrm{x}$ \\
\hline Principal Investigator & 2 & Case 2 PI2 & $\mathrm{x}$ & $\mathrm{x}$ & $\mathrm{x}$ & $\mathrm{x}$ \\
\hline Principal Investigator & 2 & Case 2 PI3 & $\mathrm{x}$ & $\mathrm{x}$ & $\mathrm{x}$ & $\mathrm{x}$ \\
\hline Principal Investigator & 2 & Case 2PI4 & $\mathrm{x}$ & $\mathrm{x}$ & $\mathrm{x}$ & $\mathrm{x}$ \\
\hline Principal Investigator & 2 & Case 2 PI5 & $\mathrm{x}$ & & $\mathrm{x}$ & $\mathrm{x}$ \\
\hline TTO Commercialisation Executive & 1 & Case 1 TTO1 & $\mathrm{x}$ & & & $\mathrm{x}$ \\
\hline TTO Commercialisation Executive & 1 & Case 1 TTO2 & $\mathrm{x}$ & $\mathrm{x}$ & & \\
\hline TTO Commercialisation Manager & 1 & $\begin{array}{ll}\text { Case } & 1 \\
\text { TTOM } & \\
\end{array}$ & $\mathrm{x}$ & & $\mathrm{x}$ & $\mathrm{x}$ \\
\hline TTO Commercialisation Executive & 2 & Case 2 TTO1 & $\mathrm{x}$ & & & $\mathrm{x}$ \\
\hline TTO Commercialisation Executive & 2 & Case 2 TTO2 & $\mathrm{x}$ & $\mathrm{x}$ & & \\
\hline TTO Commercialisation Executive & 2 & Case $2 \mathrm{TTO}_{3}$ & $\mathrm{x}$ & & & \\
\hline TTO Commercialisation Manager & 2 & $\begin{array}{ll}\text { Case } & 2 \\
\text { TTOM } & \\
\end{array}$ & $\mathrm{x}$ & & $\mathrm{x}$ & $\mathrm{x}$ \\
\hline Business Liaison Staff Member & 1 & Case 1 BLl & $\mathrm{x}$ & $\mathrm{x}$ & & $\mathrm{x}$ \\
\hline Business Liaison Staff Member & 1 & Case 1 BL2 & $\mathrm{x}$ & & & $\mathrm{x}$ \\
\hline Business Liaison Staff Member & 2 & Case 2 BLl & $\mathrm{x}$ & $\mathrm{x}$ & $\mathrm{x}$ & $\mathrm{x}$ \\
\hline Research and Enterprige Strategic Staff Member & 1 & Case $1 \mathrm{~S}$ & $\mathrm{x}$ & & & $\mathrm{x}$ \\
\hline Research and Enterprige Strategic Staff Member & 2 & Case $2 \mathrm{~S}$ & $\mathrm{x}$ & & $\mathrm{x}$ & $\mathrm{x}$ \\
\hline Innovation User & 1 & Case 1 IUl & $\mathrm{x}$ & & $\mathrm{x}$ & $\mathrm{x}$ \\
\hline Innovation Uger & 1 & Case 1 IU2 & $\mathrm{x}$ & $\mathrm{x}$ & & $\mathrm{x}$ \\
\hline Innovation Uger & 2 & Case 2 IUl & $\mathrm{x}$ & $\mathrm{x}$ & & $\mathrm{x}$ \\
\hline Innovation Uger & 2 & Case 2 IU2 & $\mathrm{x}$ & & $\mathrm{x}$ & $\mathrm{x}$ \\
\hline Govemment Commercialisation Executive & $1 \& 2$ & GOV1 & $\mathrm{x}$ & & $\mathrm{x}$ & $\mathrm{x}$ \\
\hline Government Commercialisation Executive & $1 \& 2$ & GOV2 & $\mathrm{x}$ & & & $\mathrm{x}$ \\
\hline Government Commercialisation Executive & $1 \& 2$ & GOV3 & $\mathrm{x}$ & $\mathrm{x}$ & & $\mathrm{x}$ \\
\hline Govemment Managerial Staff Member & $1 \& 2$ & GOV4 & $\mathrm{x}$ & $\mathrm{x}$ & & $\mathrm{x}$ \\
\hline Government Strategic Staff Member & $1 \& 2$ & GOV5 & $\mathrm{x}$ & & $\mathrm{x}$ & $\mathrm{x}$ \\
\hline \multirow[t]{2}{*}{ Document Type } & \multirow[t]{2}{*}{ Case } & \multirow{2}{*}{\multicolumn{2}{|c|}{$\begin{array}{l}\text { Year } \\
2008\end{array}$}} & & & \\
\hline & & & & 2010 & 2012 & 2014 \\
\hline Webaite Material & $1 \& 2$ & \multicolumn{2}{|l|}{$\mathrm{x}$} & $\mathrm{x}$ & $\mathrm{x}$ & $\mathrm{x}$ \\
\hline TTO Documents & $1 \& 2$ & \multicolumn{2}{|l|}{$\mathrm{x}$} & $\mathrm{x}$ & $\mathrm{x}$ & $\mathrm{x}$ \\
\hline Innovation Strategy Documents & $1 \& 2$ & \multicolumn{2}{|l|}{$\mathrm{x}$} & $\mathrm{x}$ & $\mathrm{x}$ & $\mathrm{x}$ \\
\hline
\end{tabular}


Accepted for Publication in R\&D Management 